\title{
Effects of altering dietary essential fatty acids on requirements for non-steroidal anti-inflammatory drugs in patients with rheumatoid arthritis: a double blind placebo controlled study
}

\author{
J J F BELCH, D ANSELL, R MADHOK, A O'DOWD, AND R D STURROCK \\ From the Centre for Rheumatic Diseases, University Department of Medicine, Royal Infirmary, Glasgow
}

SUMMARY In rheumatoid arthritis (RA) benefit from non-steroidal anti-inflammatory drugs ${ }^{\text {iv }}$ (NSAIDs) is mediated through inhibition of the cyclo-oxygenase enzyme, thereby decreasing $\mathscr{\circ}$

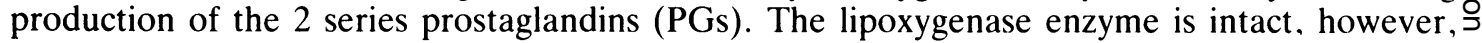
allowing leucotriene (LT) production, e.g., $\mathrm{LTB}_{4}$ (an inflammatory mediator). Treatment with $\vec{T}$ evening primrose oil (EPO) which contains $\gamma$-linolenic acid (GLA) leads to production of the $1 \frac{\Phi}{8}$ series PGs, e.g., PGE 1 , which has less inflammatory effects. Also LT production is inhibited.

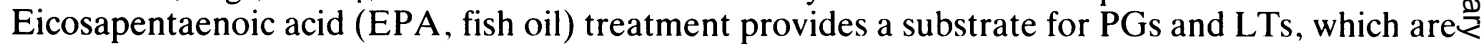
also less inflammatory. In this study 16 patients with RA were given $540 \mathrm{mg} \mathrm{GLA}$ /day (EPO), $15 \vec{\bullet}$ patients $240 \mathrm{mg}$ EPA and $450 \mathrm{mg} \mathrm{GLA} /$ day (EPO/fish oil), and 18 patients an inert oil (placebo $\$$ The aim of this study was to determine if EPO or EPO/fish oil could replace NSAID treatment 苗 RA. The initial 12 month treatment period was followed by three months of placebo for groups. Results at 12 months showed a significant subjective improvement for EPO and EPO/fish oil compared with placebo. In addition, by 12 months the patients receiving EPO and EPO/fish ٌ oil had significantly reduced their NSAIDs. After 3 months of placebo those receiving active $\mathscr{Q}$ treatment had relapsed. Despite the decrease in NSAIDs, measures of disease activity did not $\overrightarrow{0}$ worsen. It is suggested that EPO and EPO/fish oil produce a subjective improvement and allow $\exists$ some patients to reduce or stop treatment with NSAIDs. There is, however, no evidence that they act as disease modifying agents.

Key words: evening primrose oil, fish oil, prostaglandins, leucotrienes.

Inflammation is a process which occurs in tissues after sublethal injury. This is followed by production of inflammatory mediators. One such group of mediators is the eicosanoids. These are formed from precursor essential fatty acids (EFAs). The most abundant EFA in the Western diet is arachidonic acid (AA), which forms the 2 series prostaglandins (PGs), e.g., $\mathrm{PGE}_{2}$, and the 4 series leucotrienes (LTs), e.g., leucotriene $B_{4} \cdot{ }^{2}$ In general these PGs and LTs have pro-inflammatory effects. ${ }^{3}$ The ingestion of a diet rich in evening primrose oil (EPO) will increase levels of $\gamma$-linolenic acid (GLA). ${ }^{4}$ GLA is

Accepted for publication 1 July 1987.

Correspondence to $\mathrm{Dr} \mathrm{R}$ D Sturrock, Centre for Rheumatic Diseases, University Department of Medicinc, Royal Infirmary, 10 Alexandra Parade, Glasgow G31 2ER. metabolised to dihomo- $\gamma$-linolenic acid (DGLA) which produces the monoenoic PGs, e.g., $\mathrm{PGE}_{1} .5$ $\mathrm{PGE}_{1}$ has been shown to have important anti- $\frac{D}{0}$ inflammatory effects. ${ }^{5}$ DGLA cannot itself be converted to LTs but can form a 15-hydroxyl derivative $\mathcal{N}^{\circ}$ that blocks transformation of AA to LTs. ${ }^{6}$ Dietary $N$ DGLA may therefore act as a competitive inhibitor 0 of 2 series PGs and 4 series LTs. Animal studies $\omega$ have shown that such a diet can both decrease? inflammatory cell function and suppress inflammation. $^{7-9}$

High dietary levels of another EFA, eicosapentae $\stackrel{\stackrel{\mathscr{P}}{?}}{?}$ noic acid (EPA), would provide a substrate for $\frac{7}{0}$ production of the 3 series PGs and LTs of the $5 \frac{\vec{D}}{2}$ series. ${ }^{310}$ The potency of $\mathrm{LTB}_{5}$ in inducing leuco- $\frac{\stackrel{?}{\mathrm{P}}}{\mathrm{D}}$ cyte aggregation is $10 \%$ of the potency of $\mathrm{LTB}_{4} \cdot{ }^{11} \stackrel{\square}{\varrho}$ 
Again, animal studies have suggested that an antiinflammatory effect can be obtained by increasing dietary EPA. ${ }^{12} 13$ The effect of altering EFAs in the diet of humans with inflammatory disorders has, however, been less well studied. Wright and Burton have shown a significant clinical improvement in the manifestation of eczema in patients treated with EPO ${ }^{14}$ and Baker, Krakauer, and Zurier have demonstrated a reduction in human synovial cell proliferation in vitro by addition of DGLA. ${ }^{15}$ Two clinical studies of EPO in rheumatoid arthritis (RA) proved disappointing. ${ }^{1617}$ The respective doses of EPO were low and the study periods short, however.

Payan et al have shown a decrease in leucocyte activity in humans after treatment with EPA, ${ }^{10}$ and Kremer et al suggested that patients with RA had obtained benefit after such treatment. ${ }^{18}$

Another benefit might be expected from manipulating essential fatty acids in the diet of patients with RA. 'First line' treatment for RA is with nonsteroidal anti-inflammatory drugs (NSAIDs). These drugs act by inhibiting the cyclo-oxygenase enzyme and therefore decreasing the production of proinflammatory prostaglandins from AA. AA, however, is also metabolised by another enzyme, the lipoxygenase enzyme, into the LTs. ${ }^{3}$ Treatment with NSAIDs may therefore ameliorate the PG mediated aspects of inflammation, but will allow those dependent on lipoxygenase action to proceed unchecked. Furthermore, NSAIDs may produce side effects, e.g., gastric irritation, as a result of decreased PG production. Theoretically it should be possible to substitute EPO or EPA for NSAID treatment; this would allow a decrease in the proinflammatory PGs and LTs metabolised from AA and, as other less inflammatory PGs (e.g., PGE $_{1}$ ) would be increased, there should be no gastric side effects from this therapy.

The aim of our study, therefore, was to determine whether EPO or an EPO/fish oil combination containing EPA could be substituted for NSAID therapy without any deterioration in clinical symptoms. The study was double blind and placebo controlled.

\section{Patients and methods}

PATIENTS

Forty nine patients with classical or definite RA as defined by American Rheumatism Association criteria were enrolled in the study after informed consent had been obtained. Permission for the study had been received from the regional ethical committee. All patients required first line (NSAID) therapy for control of their symptoms, but none was considered severe enough to warrant second line therapy. Sixteen patients received EPO treatment taken as 12 capsules/day, providing a total daily dose of $540 \mathrm{mg} \mathrm{GLA} ; 15$ received EPO/fish oil capsules (12/day), providing a total daily dose of $450 \mathrm{mg}$ GLA and $240 \mathrm{mg}$ EPA; 18 patients received 12 capsules/day of placebo (liquid paraffin). In addition, all capsules contained vitamin $\mathrm{E}$ as an antioxidant (dose $120 \mathrm{mg} /$ day). As it was considered that 12 capsules at one time might be inconvenient the patients were instructed to take them intermittently throughout the day. Most selected four capsules three times/day, though some patients took six twice/day or three capsules four times/day.

\section{A PS ULES}

All three types of capsules were supplied by Efamol Ltd and were visually identical. They were issued to the patients in a randomised double blind fashion.

\section{STUDY DESIGN}

The duration of study was 15 months. For the first three months of the study the patients were instructed to take the 12 capsules of oil a day, plus their full dose of NSAID. From three to six months in particular, but also up to 12 months, the patients were instructed to decrease or stop their NSAID. From 12 to 15 months they were told to maintain, if possible, the current dose of NSAID. Patients were only to decrease or stop NSAIDs if this could be done without exacerbation of RA symptoms. At 12 months all patients received placebo capsules (12/day) without vitamin E. As this was part of the study design investigators were aware of the treatment in all patients from 12 to 15 months; the patients, however, remained blinded. The aim of this placebo phase was to assess whether any improvement was due to the antioxidant and radical scavenging effect of the vitamin $E,{ }^{19}$ and also to monitor relapse. The patients attended the clinic at monthly intervals for the first six months and thereafter at three-monthly intervals.

\section{CLINICAL ASSESSMENT}

Full metrological assessment was carried out before the start of the study and at $3,6,12$, and 15 months. The duration of morning stiffness in minutes, the grip strength of left and right hands $(\mathrm{mmHg}$, mean of three readings), and the Ritchie articular index ${ }^{20}$ were noted. The patients also completed a $10 \mathrm{~cm}$ visual analogue pain scale, and the occurrence of side effects was recorded. In addition, the patients were asked to record whether they obtained benefit or otherwise from the treatment.

B L OOD TESTS

Blood was sampled before the start of the study and 
again at 3,6, 12, and 15 months. The erythrocyte sedimentation rate (ESR) was measured, as were C reactive protein (CRP) levels. Haemoglobin $(\mathrm{Hb})$ and rheumatoid factor estimation were also carried out. Samples from month 0, 6 months, and 12 months were stored at $-70^{\circ} \mathrm{C}$ for later analysis of plasma and red cell membrane EFA levels; this enabled a check of patient compliance.

\section{STATISTICAL ANALYSES}

Comparability between the treatment groups was analysed with the Mann-Whitney U test. Sequential analyses were carried out using the two tailed paired Wilcoxon test.

\section{Results}

Table 1 shows the comparability of the different treatment groups, both for clinical and laboratory measurements, at the start of the study. No significant differences in the patient populations were witnessed. Table 2 shows the number of patients withdrawn from the study by 12 months. One patient in the EPO group and two in the EPO/fish oil group were withdrawn owing to increasing symptoms of RA, compared with $10 / 18$ of the placebo patients (both $\mathrm{p}<0 \cdot 001$, Mann-Whitney).

The results from all patients who were withdrawn were analysed throughout the study on an intention to treat basis. The subsequent results are expressed as a percentage of baseline so that the different group totals can be more easily compared.
Fig. 1 is a compilation of results showing the dose of NSAID in all three groups before the start of $\frac{\square}{\infty}$. treatment and at 3, 6, 9, and 12 months. As one EPO and three placebo patients were not taking NSAIDs at the start of the study they have not beeno

Table 1 Comparability of groups*

\begin{tabular}{llll}
\hline & Placebo & EPO & $\begin{array}{l}\text { EPO/ } \\
\text { fish oil }\end{array}$ \\
\hline Age (years) & 48 & 46 & 53 \\
& $(30-74)$ & $(35-68)$ & $(28-73)$ \\
Duration (years) & 5 & 5 & 5 \\
& $(1-20)$ & $(1-18)$ & $(1-25)$ \\
Sex M:F & $1: 17$ & $1: 15$ & $4: 11$ \\
Morning stiffness (min) & 31 & 47 & 31 \\
& $(0-240)$ & $(0-120)$ & $(0-240)$ \\
Grip strength & & & \\
(mmHg, right hand) & 106 & 116 & 105 \\
& $(53-260)$ & $(58-207)$ & $(50-300)$ \\
Articular index & 6 & 5 & 7 \\
& $(0-24)$ & $(0-14)$ & $(0-12)$ \\
Visual analogue scale (cm) & $2 \cdot 3$ & $3 \cdot 6$ & $3 \cdot 0$ \\
& $(0-8 \cdot 0)$ & $(0-9 \cdot 5)$ & $(0-7 \cdot 3)$ \\
ESR (mm/h) & 30 & 22 & 26 \\
& $(3-75)$ & $(4-81)$ & $(4-55)$ \\
CRP (mg/l) & 19 & 19 & 13 \\
& $(8-76)$ & $(10-43)$ & $(10-38)$ \\
Hb (g/l) & 118 & 126 & 138 \\
RF (titre) & $(100-155)$ & $(88-149)$ & $(117-16850$ \\
& $1 / 16$ & $1 / 128$ & $1 / 128$ \\
& $(0-1024)$ & $(0-1024)$ & $(0-1024)$
\end{tabular}

*Median (range).

$\mathrm{ESR}=$ erythrocyte sedimentation rate; $\mathrm{CRP}=\mathrm{C}$ reactive protein; $\mathrm{Hb}=$ haemoglobin; $\mathrm{RF}=$ rheumatoid factor .

\section{EPO / NSAID DOSAGE}

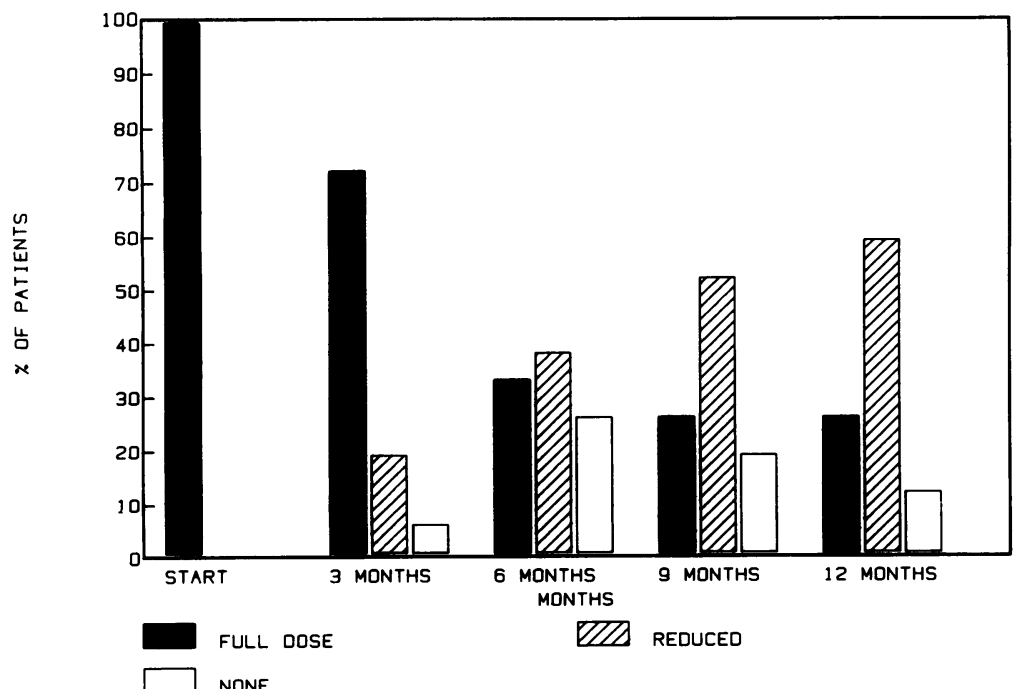

Fig. 1a 
included in these analyses. Eleven out of 15 EPO patients and 12 out of $15 \mathrm{EPO} /$ fish oil patients reduced or stopped their NSAIDs by 12 months, compared with five out of 15 of the placebo patients $(\mathrm{p}<0.003, \mathrm{p}<0.002, \mathrm{p}<0.05$ respectively, paired Wilcoxon).

Fig. 2 shows a compilation of results for the clinical measurements in all three groups. No significant change was seen over the study period.
Table 2 Patients withdrawn from the study by 12 months

\begin{tabular}{lcll}
\hline & Placebo & EPO & $\begin{array}{l}\text { EPOI } \\
\text { fish oil }\end{array}$ \\
\hline Increasing RA symptoms & 10 & 1 & 2 \\
Gastrointestinal upset & 0 & 2 & 0 \\
Total & 10 & 3 & 2 \\
\hline
\end{tabular}

\section{EPO-MARINE / NSAID DOSAGE}

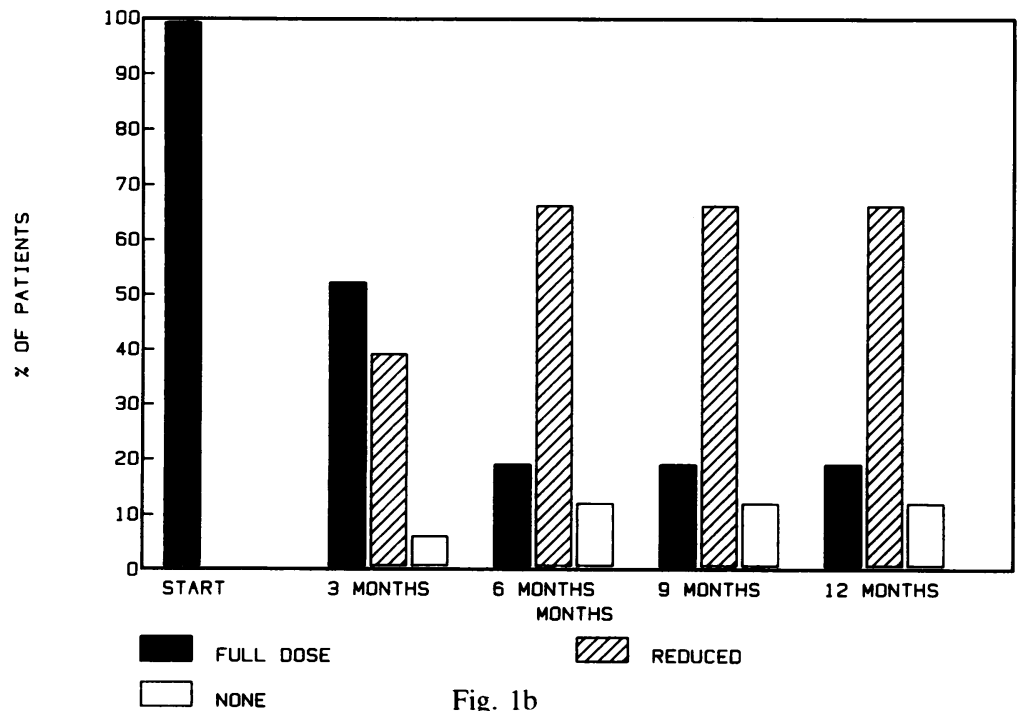

Fig. 1b

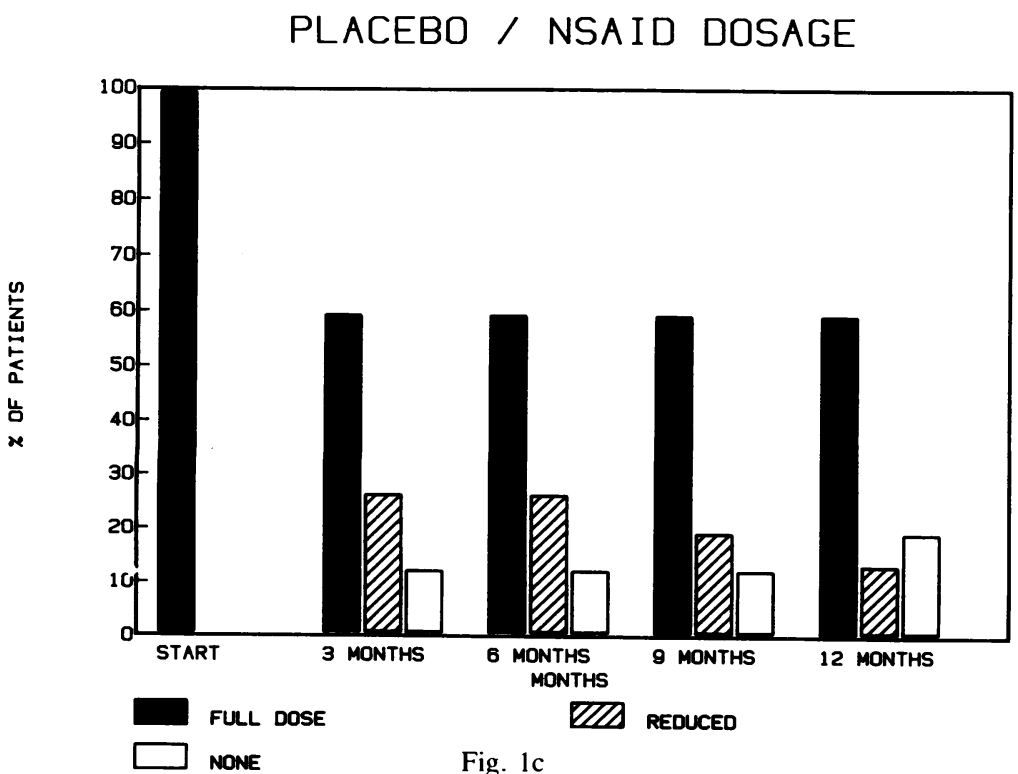

Fig. 1 NSAID treatment in the three groups of patients.

Fig. 1c 
Fig. 3 shows the three sets of results from the laboratory measurements; again no significant change in results was noted over the study period, though, as with the clinical results, the EPO group appeared to fare better.

Fig. 4 shows the subjective response for the three patient groups over the study period. As one would̄ expect, the control group did show a marked. placebo response of about $40 \%$ at six months:? Surprisingly this persisted throughout the study though it fell to about $30 \%$ at 12 months. Despite the absence of real change in objective measures of

EPO / CLIN RESPONSE

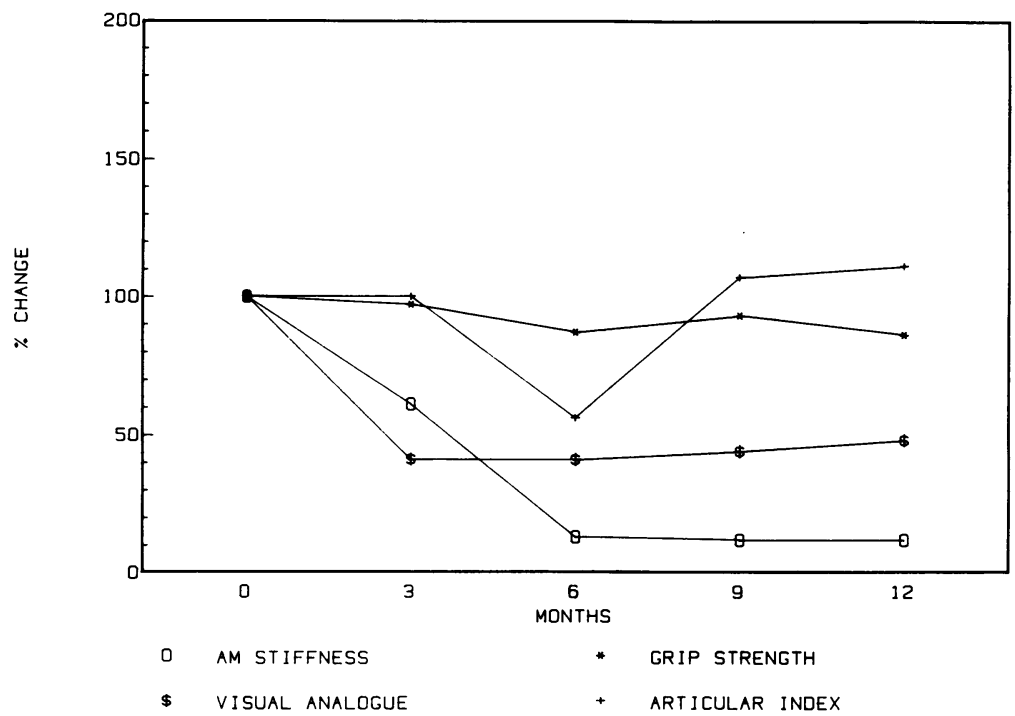

Fig. 2a

\section{EPO-MARINE / CLIN RESPONSE}

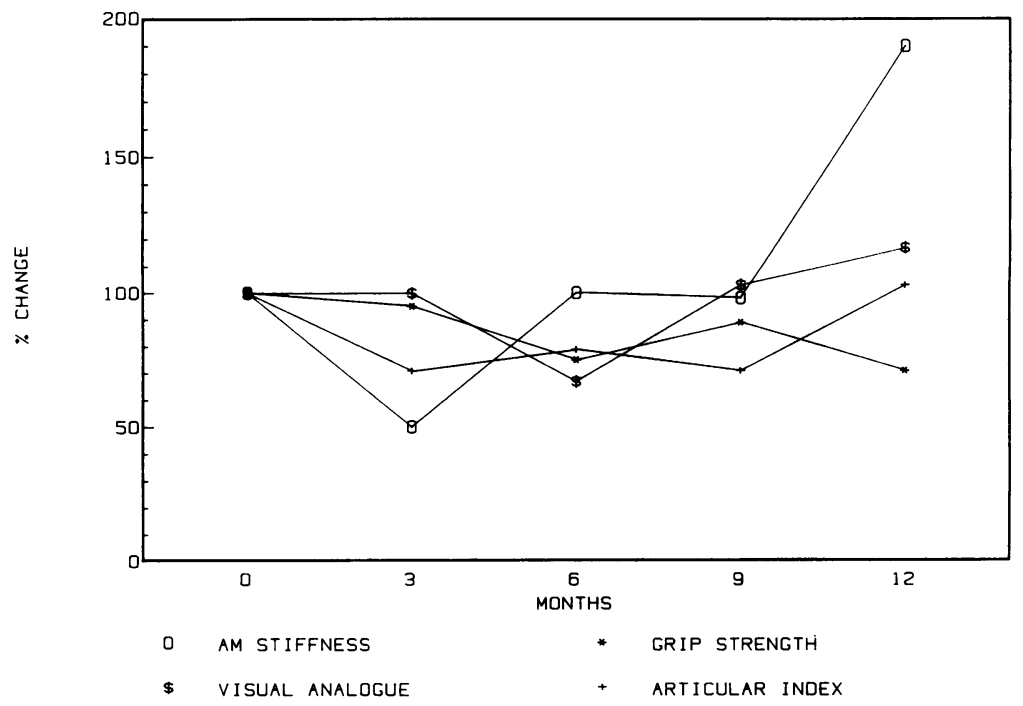

Fig. 2b 


\section{PLACEBO / CLIN RESPONSE}

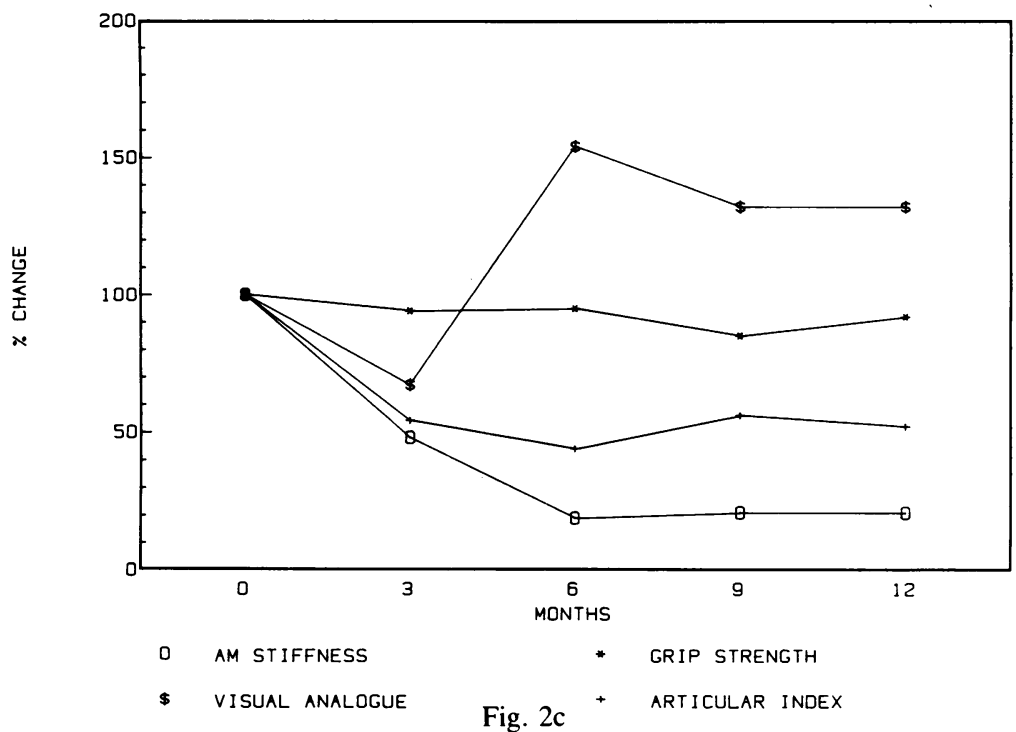

Fig. 2 Clinical measurements in the three groups of patients.

disease activity, $94 \%$ of the EPO and $93 \%$ of the $\mathrm{EPO} /$ fish oil group felt a subjective improvement in their condition at 12 months. Most patients on active treatment recorded an increase in their general sense of wellbeing.

After the three month placebo phase all the EPO patients and $80 \%$ of the EPO/fish oil patients had either returned to baseline or become worse. This compares with a relapse rate of only $14 \%$ in the placebo group.

Four patients experienced side effects. Two in the EPO group, one with nausea and one with diarrhoea, required to be withdrawn from the study at two and one months respectively (Table 2). Two patients in the EPO/fish oil group also experienced side effects, nausea and headache, but neither patient required to be withdrawn from the study.

Estimation of fatty acid levels by high performance liquid chromatography in plasma and red cell membranes confirmed compliance in all subjects apart from one EPO/fish oil patient. This patient was one of the two from the group who were withdrawn because of increasing RA symptoms.

\section{Discussion}

There are good theoretical reasons for suggesting that altering dietary EFA may produce anti-inflammatory effects similar to cyclo-oxygenase inhibition by NSAIDs. 578913 Indeed, additional effects might be expected because of the alteration in leuco- triene production not seen with NSAIDs. ${ }^{6}$ Furthermore, fewer gastric side effects would be expected as PGs of other series, though less inflammatory, would be available for gastric cytoprotection. ${ }^{5}$

In this study we have shown that it was possible for some patients with RA to decrease or stop NSAID treatment when EPO or EPO/fish oil was given. This was achieved with no deterioration in clinical or laboratory measures of RA activity. A decrease in NSAID dose was also seen in the placebo group, though this was much less marked. In combination with the $30 \%$ placebo subjective response, this stresses the importance of placebo controlled studies in RA. Four patients (three placebo and one EPO) were not receiving any NSAID at the start of the study. These patients had stopped NSAID treatment without medical advice, having developed dyspepsia since their last clinic visit. Because of the severity of the gastrointestinal symptoms it was decided to enrol them into the study.

It was interesting that, despite the lack of objective improvement in symptoms on the active oils, there was a very definite subjective improvement. The mechanism of this is unclear, but two alternative explanations are possible. EPO has had some success in treating premenstrual tension and certainly it is known to alter brain PG production. ${ }^{21} 22$ $\mathrm{PGE}_{1}$ may have an antidepressant effect, ${ }^{23}$ and the increase in $\mathrm{PGE}_{1}$ after EPO treatment may be responsible for the subjective response witnessed in 

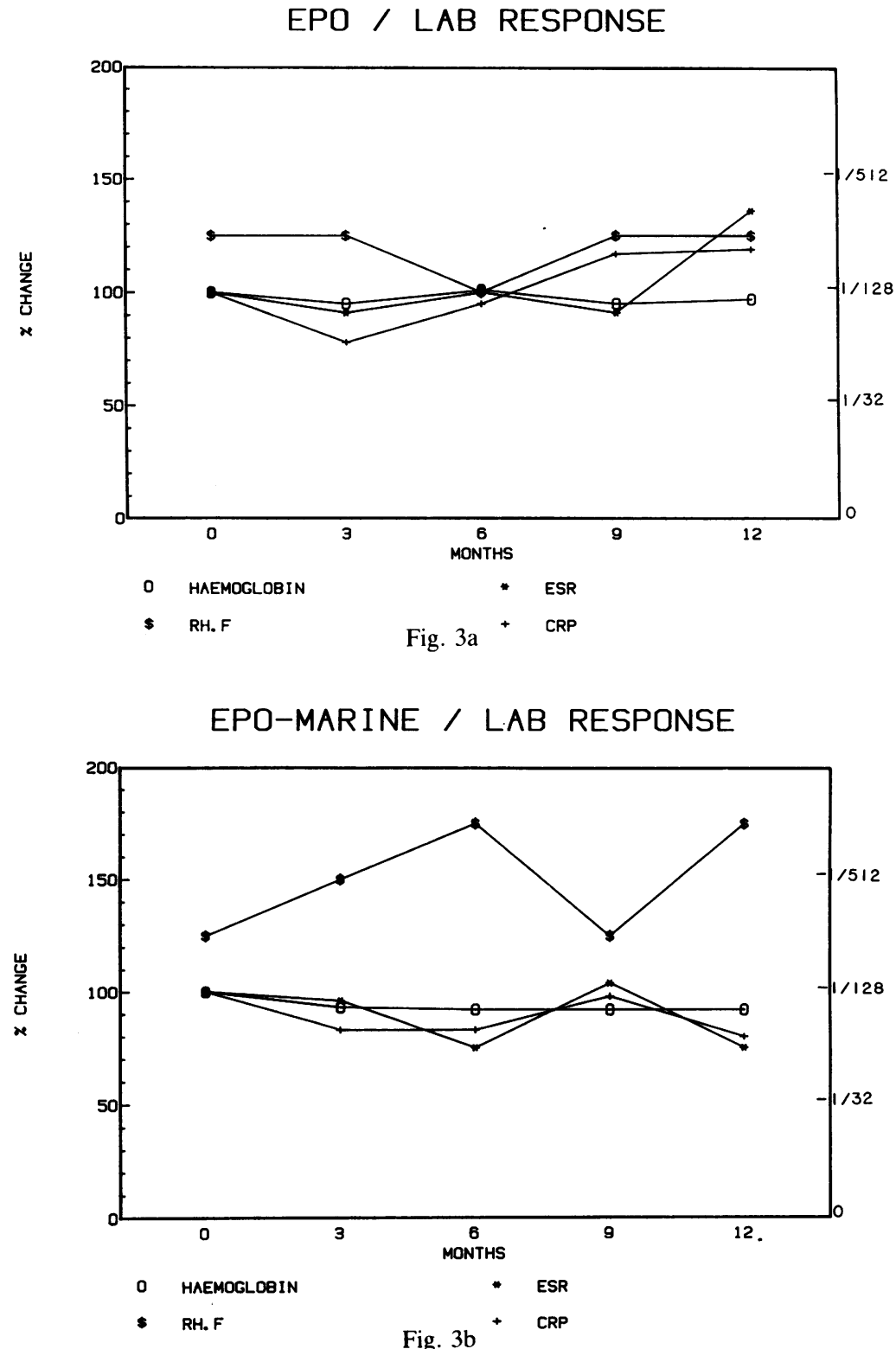

Fig. $3 b$

the study. An alternative explanation could be that decreasing NSAID therapy may remove some negative effect of these drugs on the patient's wellbeing.

The relapse in response witnessed after substitution with placebo capsules was interesting. The fact that only $14 \%$ of the placebo group relapsed makes it very likely that spontaneous remission had occurred in the other placebo patients; all the patients in the EPO group either felt worse or returned to pre-study level symptoms. Interestingly, althouglw almost $80 \%$ of the EPO/fish oil group relapsed ob placebo, $20 \%$ maintained their improvement. If may be that loss of EPA from the cell membrane takes longer to occur than with DGLA. Unfor tunately, fatty acid analyses of the 15 month samples were not carried out so this hypothesis remain $\bar{s}$ unchecked. The results from our work appear to b $\vec{\otimes}$ in contrast with those obtained by Brown et al ${ }^{16}$ an $\Phi^{1}$ 


\section{PLACEBO / LAB RESPONSE}

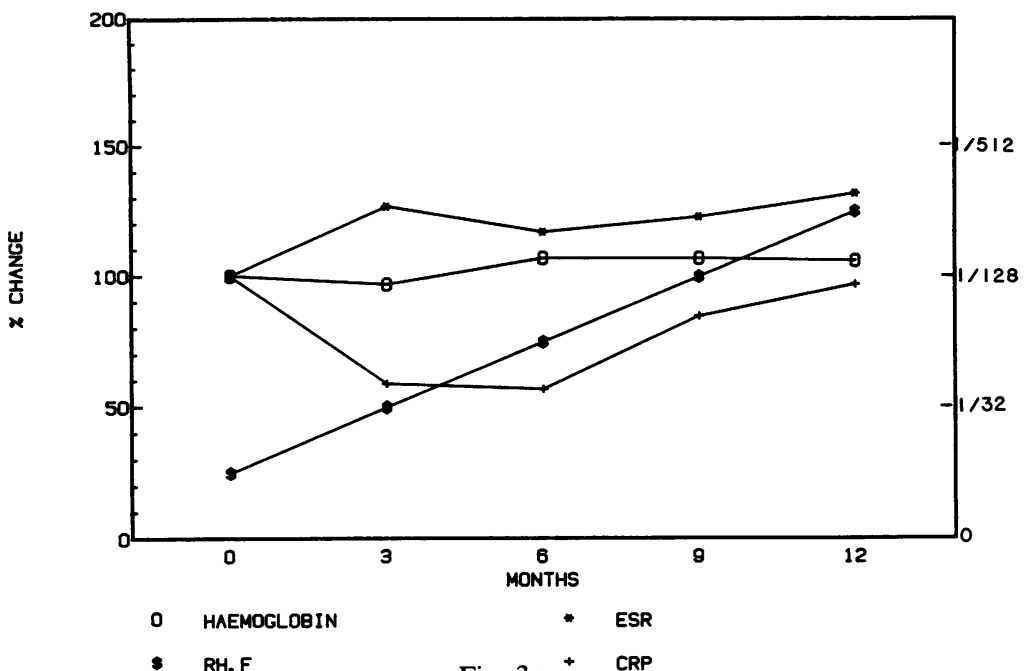

Fig. 3 Laboratory measurements in the three groups of patients.

- RH. F

Fig $3 c+C R P$

SUBJECT IVE RESPONSE

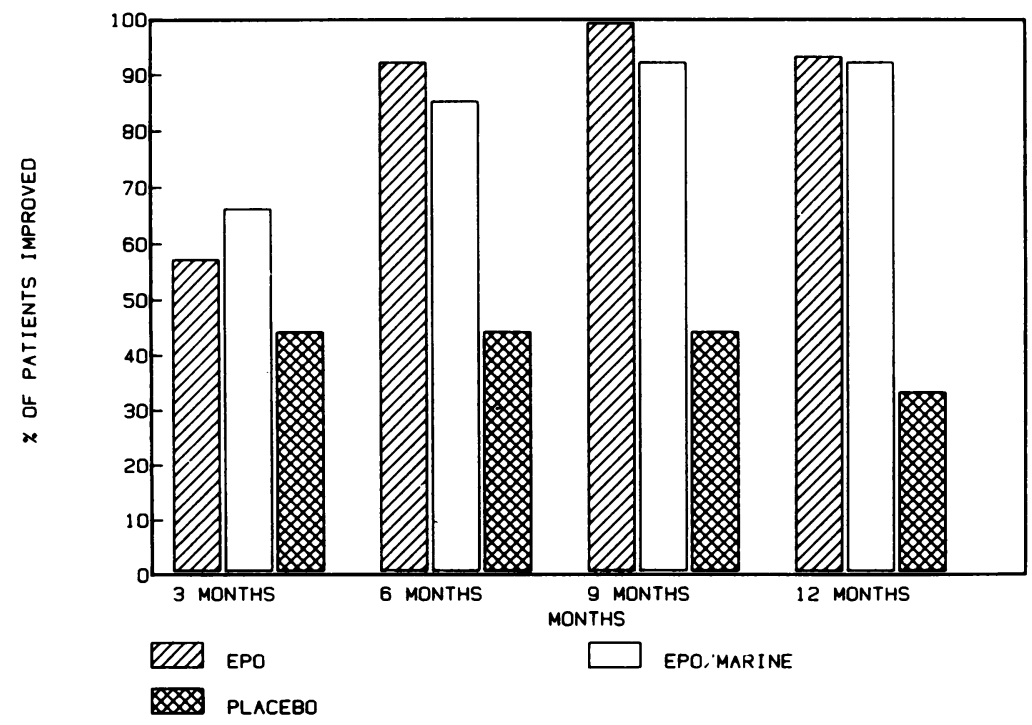

Fig. 4 Subjective response in the three groups of patients.

Hansen et al. ${ }^{17}$ Both these studies used a lower dosage regimen of EPO and in both the study period was only three months. As can be seen from our data, improvement is most marked from six months onwards. In addition, their patients stopped NSAIDs abruptly before the start of the studies. This may have caused a flare in the patients' symptoms in the first weeks as it is unclear how long
EFA treatment should be undertaken before alteration in PG and LT production occurs. This combination of NSAID withdrawal and short treatment period may explain the authors' negative findings. It is also possible that these two studies looked at different patient populations. All of our patients had mild RA as shown by the clinical and laboratory values in Table 1 . In contrast, these other 
two groups appeared to study patients with more severe disease; in particular the group studied by Hansen et al had markedly higher ranges of ESR and much lower ranges of $\mathrm{Hb} .^{77}$

Kremer et al showed benefit in RA with EPA treatment ${ }^{18}$; our work cannot be compared with this study, however, as we used EPA only in combination with EPO. Nevertheless, he did show an improvement at three months and certainly this agrees with our data, where the combined therapy did seem to produce an earlier response. There did not, however, appear to be any other differences between the EPO and the EPO/fish oil groups. It is possible that the addition of EPA had no effect and the lower dose of EPO was sufficient to allow NSAID withdrawal; it is also possible that the fish oil contributed to the effect of the EPOs, thus making the two groups indistinguishable. In retrospect a more suitable study design would appear to have been EPO versus fish oil versus placebo; previous work, however, had suggested a synergism between the two $\mathrm{EFAs}^{24}$ which we wished to investigate.

In conclusion, therefore, we have shown that it is possible to decrease or stop NSAIDs in some patients with RA by introducing EPO or EPO/fish oil treatment. It should be noted, however, that, although the patients claimed a subjective improvement, there was no change in any of the measurements conventionally used to measure disease activity. It is unlikely, therefore, that long term therapy with these EFAs would alter the course or prognosis of the disease. It would seem that these oils may be best used in clinical situations where NSAID therapy should be avoided, for example in patients with peptic ulceration or renal impairment.

We would like to thank Dr Charles Stewart of Efamol Ltd for providing the capsules for the study. This work has been supported by a grant from Action Research for the Crippled Child, and their help is gratefully acknowledged.

\section{References}

1 Jantti J, Isomaki $H$, Laitinen $O$, Nikkari $T$, Seppala E, Vapaataio $\mathrm{H}$. Linoleic acid treatment in inflammatory arthritis. Int J Clin Pharmacol Ther Toxicol 1985; 23: 89-91

2 Epstein M, Lifschitz M, Rappaport K. Augmentation of prostaglandin production by linoleic acid in man. Clin Sci 1982; 62: $565-71$.

3 Belch J J F. The role of leukotrienes as mediators of inflammation. In: Moll J M H, Sturrock R D, eds. Recent advances in rheumatology. London: Churchill Livingstone, 1986: 37-51.

4 Fisher J M, Donegan D R, Leon H, Willis A L. Effects of prostaglandins and their precursors in some tests of hacmostatio function. Prog Lipid Res 1982; 20: 799-805.

5 Martin J, Stackpool A. Anti-PGE, antibodies inhibit in-vivo development of cell mediated immunity. Nature 1981: 294 456-8.

6 Voorlees J J. Leukotrienes and other lipoxygenase products the pathogenesis and therapy of psoriasis and other dermatoses Arch Dermatol 1983; 119: 541-7.

7 Elliott G R, Adolfs M J P, van Batenburg M. Bonta I L $\frac{\bar{\omega}}{.}$ Linoleic and dihomo-gamma-linolenic acids modulate granug loma growth and granuloma macrophage eicosanoid releasc Eur J Pharmacol 1986; 124: 325-9

8 Godfrey D G, Stimson W H. Watson J. Belch J J F, Sturroc R D. The modulation of auto-immunity in the MRL-mp-1 pr/1 pr. mouse by dietary fatty-acid supplementation. Prog Lipid Res 1986; 25: 288-93

9 Delbarre F, de Gery A. Effet immuno-moderateur, des lipideñ extraits de graines d'Oenothara sur la polyarthrite à adjuvan chez le rat. Rheumatologie (Paris) 1980; 10: 361-3.

10 Payan D G, Wong M Y S, Chernov-Rogan T, et al. Alterations in human leukocyte function induced by ingestion of eicosapentanoic acid. J Clin Immunol 1986; 6: 4(1)2-10.

11 Prescott S M. The effect of eicosapentanoic acid on leukotrieno $\mathrm{B}_{4}$ production by human neutrophils. J Biol Chem 1984; 259? 7615-21.

12 Karmali R A, Davies J, Volkman A. The effect of MaxEP क्ष supplementation in the salmonella associated arthritis model iq Lewis $\mathrm{xBNF}_{1}$ rats. Prostaglandins Leukotrienes Med 1982: 8 437-9.

13 Prickett J D, Robinson D R. Steinberg A D. Effects of dietary enrichment with eicosapentanoic acid upon autoimmune neptro ritis in female NZBxNZW/F, mice. Arthritis Rheum 1983. 용 133-9.

14 Wright S, Burton J L. Oral evening-primrose-seed oil impre atopic eczema. Lancet 1982; ii: $1120-2$

15 Baker D G. Krakauer R A, Zurier R B. Reduction of huma synovial cell proliferation by dihomogamma linolenic acid. Clia Res 1986; 34: 615A.

16 Brown J, Sim A K. De Ceular K, McLeod M. El-Ghobary A Fo Dick W C. Naudicelle in patients with rhcumatoid arthritis Therapeutique 1980; 50: 355-7.

17 Hansen T M. Lerche A. Kassis V. Lorenzen I. Sondergaard Treatment of rheumatoid arthritis with prostaglandin $E_{1}$ pre cursors cis-linoleic acid and gamma-linolenic acid. Scand Rheumatol 1983; 12: 85-8.

18 Kremer J M, Biganoctte J, Michalek A V, et al. Effects of manipulation of dietary fatty acids on clinical manifestations of rheumatoid arthritis. Lancet 1985; i: $184-7$.

19 Szczeklik A, Gryglewski R J, Domagala B, Dworski R, Basist M. Dietary supplementation with vitamin $\mathrm{E}$ in hyperlipe proteinemias: effects on plasma lipid peroxides, anti-oxidan activity, prostacyclin generation and placelet aggregabilityo Thromb Haemost 1985; 54: 425-30.

20 Ritchie D M, Boyle J A. McInnes J M. et al. Clinical studief with an articular index for the assessment of joint tenderness iII. patients with rheumatoid arthritis. $Q J$ Med 1968; 37: 393-406

21 O'Brien P M. Premenstrual syndrome: a review of the presen $\Phi$ status of therapy. Current Therapy (Australia) 1983; 24: 105-12N

22 Brush M G. Nutritional approaches to the treatment premenstrual syndrome. Nutr Health 1983; 2: 203-9.

23 Parmigiani P. Evening primrose oil (Efamol) and captopril it schizophrenia: a preliminary report. In: Horrobin D F, edf Clinical uses of essential fatty acids. Montreal: Eden Press. 198 209-14.

24 Juan H, Sametz W. Dihomo-gamma-linolenic acid increases the metabolism of eicosapentanoic acid in perfused vascular tissuc $\square$ Prostaglandins Leukotrienes Med 1985; 19: 63-78.

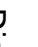

